\title{
A STUDY ON CORROSION PROTECTION OF ALUMINIUM SURFACE BY CHLORINE SUBSTITUTED PIPERIDIN-4-ONE IN SULFURIC ACID MEDIUM
}

\author{
K. Rathidevi ${ }^{1, *}$, S. Jyothi ${ }^{1}$, D. Jalajaa ${ }^{1}$ and S. Karthikeyan ${ }^{2}$ \\ ${ }^{1}$ Assistant Professor, Department of Science and Humanities, Kumaraguru College of \\ Technology, Coimbatore-641 049, Tamilnadu, India. \\ ${ }^{2}$ Assistant Professor, Department of Civil Engineering, Kumaraguru College of Technology, \\ Coimbatore-641 049, Tamilnadu, India. \\ *E-mail: rathidevi.k.sci@kct.ac.in
}

\begin{abstract}
The corrosion protection of aluminium surface by the inhibitor 3, 5-diethyl 2, 6-diphenyl p-chloro Piperidin-4-one in $1 \mathrm{~N}$ Sulfuric acid medium is examined by using mass loss measurement. Electrochemical studies are used to analyze the corrosion inhibiting nature of the inhibitor. The experimentation is carried out at room temperature. The findings of mass loss measurement indicate that the studied organic inhibitor molecule exhibit corrosion inhibition efficiency on aluminium in sulfuric acid medium. The findings of polarization studies show that inhibitor 3, 5-diethyl 2, 6diphenyl p-chloro Piperidin-4-one behaves as both anodic and cathodic type corrosion inhibitor. From the increasing value of charge transfer resistance $\left(\mathrm{R}_{\mathrm{ct}}\right)$ with decreasing nature of double layer capacitance $\left(\mathrm{C}_{\mathrm{dl}}\right)$ value the corrosion inhibiting nature is observed to increase with the increase of inhibitors concentration at constant acid strength. The adsorption of the inhibitor 3, 5-diethyl 2, 6-diphenyl p-chloro Piperidin-4-one on aluminium obeys Langmuir's adsorption isotherm.

Keywords: Inhibition Efficiency, DEPCPN, Mass Loss, Polarization, Organic Inhibitor Molecule, Impedance studies

๑ RASĀYAN. All rights reserved
\end{abstract}

\section{INTRODUCTION}

The uprising applications of metals in all engineering sectors make to pay more attention to its maintenance. As aluminium and its alloys are used in aerospace and in some other industries, its corrosion studies have been received more attention by researchers ${ }^{1}$. It is important to observe the consequences of corrosion of metals and its control than it was done earlier. As an environmental factor plays a significant role in material selection it is very essential to study the influence of environment on corrosion tendency of the metal. Various studies are employed to protect the metals from different types of corrosion ${ }^{1}{ }^{2,}$, The most important one is applying inhibitors in the corrosive environment. The usage of inhibitors to control corrosion is an economical way to protect metals from a corrosive environment ${ }^{3}$. These inhibitors form a protective covering layer on the metal surface which fight against the corrosion. Several studies ${ }^{4,5}$ ascertained that the role of inhibitors in control of corrosion. The present work is focusing to study the corrosion protection nature of 3, 5-diethyl 2, 6-diphenyl $p$-chloro Piperidin-4-one (DEPCPN) on aluminium surface in $1 \mathrm{~N}$ sulfuric acid solution by mass loss method, potentiodynamic polarization and electrochemical impedance spectroscopy (EIS) techniques.

\section{Preparation of Aluminium Specimen}

\section{EXPERIMENTAL}

Mass loss experiments were conducted using a rectangular aluminium specimen having the dimension of $1.5 \mathrm{~cm} \mathrm{x} 4 \mathrm{~cm}$. Near the upper edge of the coupon a hole with the diameter of $0.5 \mathrm{~cm}$ was drilled in which the specimen is made to hook in the glass rod for immersion. In the case of electrochemical studies an

Rasayan J. Chem., 12(2), 565-570(2019)

http://dx.doi.org/10.31788/RJC.2019.1224098

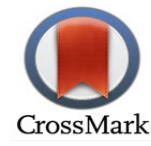


RASĀYAN J. Chem.

Vol. 12 | No. 2 |565 - 570| April - June | 2019

aluminium rod which is having an exposed area of $1 \mathrm{~cm}^{2}$ were used. The specimens contain $99.9 \%$ aluminum.

\section{Preparation of Inhibitor}

Mannich reaction ${ }^{6}$ is used to synthesize the organic inhibitor 3, 5-diethyl 2, 6-diphenyl $p$-Chloro Piperidin4-one (DEPCPN) which is represented in Fig-1.To a solution of dry ammonium acetate $(9.8 \mathrm{~g}, 0.125 \mathrm{~mole})$ in methanol $(30 \mathrm{ml}) \mathrm{P}$-chlorobenzaldehyde $(29.0 \mathrm{~g}, 0.25 \mathrm{~mole})$ and dipropyl ketone $(9.0 \mathrm{~g}, 0.125 \mathrm{~mole})$ is added. This solution mixture is boiled.It remained undisturbed for overnight at $26 \pm 1^{\circ} \mathrm{C}$. To the above solution conc.hydrochloric acid $(13 \mathrm{ml})$ is then added. The precipitate is then filtered and washed with ethanol-ether (1:5). Recrystallization is done with ethanol. Mp is $224^{\circ} \mathrm{C}$ (Lit mp 224-226 ${ }^{\circ} \mathrm{C}$ ).

The above precipitate with acetone is again mixed with ammonia (1:1), by adding an excess of water the free base is settled down as a precipitate. Recrystallization is done with ethanol. $\mathrm{Mp} 97^{\circ} \mathrm{C}\left(\mathrm{Lit} \mathrm{mp} 96-97^{\circ} \mathrm{C}\right)$. The structure of the inhibitor (DEPCPN) is given in Fig.2.
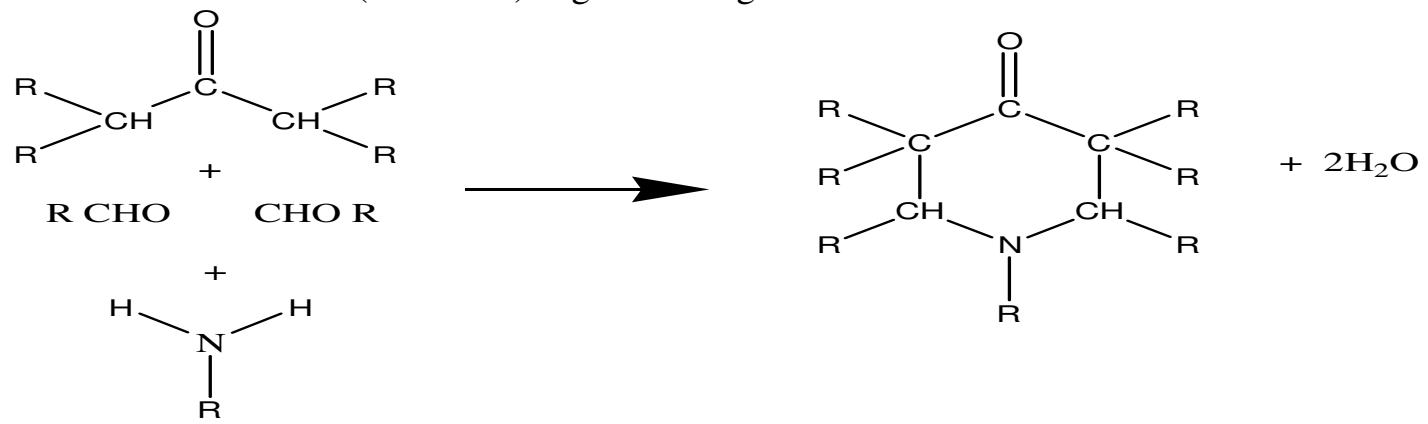

Fig.-1: The Synthetic Route used for the Preparation of the Inhibitor DEPCPN

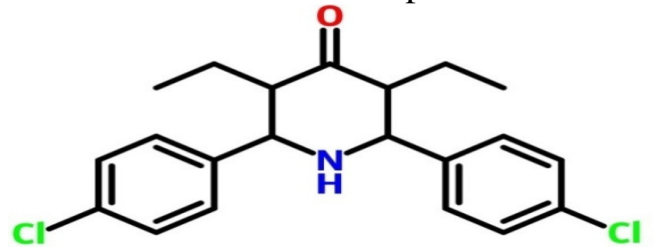

Fig.-2: Structure of the Inhibitor - 3, 5-diethyl 2, 6-diphenyl p-chloro Piperidin-4-one (DEPCPN)

\section{Mass Loss Measurement}

The mass loss measurement is the simplest and longest-established method of calculating corrosion losses in metals. ${ }^{7}$ Though being the oldest method currently in use, this method is commonly employed to study the weight loss of corroding metals. This method is the direct measure to find out the rate of corrosion of a metal in an aqueous medium. It is conducted with the rectangular aluminium specimen in the form of $1.5 \mathrm{~cm} \mathrm{x} 4 \mathrm{~cm}$. Emery sheets are used to clean the specimens. Washing is done using distilled water. Acetone is used to degrease the specimens, then dried. The weight of the specimens was accurately noted in the presence and absence of DEPCPN. They were in immersion with the test solutions for a quantified period of time. After a specified time period the specimens were taken away from the test solution, then rinsing is done using water. The specimens were dried with warm air and kept in a desiccator. The weight of the specimens was noted again to calculate the weight difference ${ }^{8}$. This study is used to calculate the \% of inhibition efficiency (\% IE), the rate of corrosion (CR) and surface coverage $(\theta)$.

\section{Electrochemical Studies}

This study includes electrochemical impedance and potentiodynamic polarization methods to study the corrosion inhibition nature of the inhibitor (DEPCPN).

\section{Instrument Description}

The analyzer used for this study is EG\&G electrochemical impedance analyzer, model 6310 . In order to carry out electrochemical studies a cell assembly with three-electrode is used. The three electrodes used are aluminium, platinum and saturated calomel electrodes which act as a working electrode, counter and 
reference electrodes respectively. The potentiodynamic polarization and electrochemical impedance were done when the potential of the working aluminium electrode reaches the steady value $\mathrm{E}_{\text {corr }}$ (by varying not $<$ than $2 \mathrm{mV} / \mathrm{min}$ ). By sweeping the potential in the predetermined range from -ve to +ve at a rate of 10 $\mathrm{mV} / \mathrm{sec}$, the potentio dynamic polarization study was done $\mathrm{e}^{9}$. The various corrosion kinetic parameters are obtained from this study on aluminium with and without adding the inhibitor of different concentration. Electrochemical impedance analysis was done with AC signal having an amplitude of $5 \mathrm{mV}$.

\section{RESULTS AND DISCUSSION}

From the mass loss measurement, the efficiency of inhibition (\% $\%$ IE), the rate of corrosion (CR) is determined. The $\%$ Inhibition efficiency and rate of corrosion for DEPCPN on aluminium in $1 \mathrm{~N} \mathrm{H}_{2} \mathrm{SO}_{4}$ at room temperature $\left(28^{\circ} \pm 1\right)$ are given in Table- 1 . The findings in tabulation show that $\%$ IE increases up to $2 \mathrm{mM}$ concentration of DEPCPN beyond that the \%IE starts to decline. This is due to the withdrawal of DEPCPN from the metal surface. It is pictorially represented in Figures- 3 and 4. This suggests that the organic inhibiting molecule gets assimilated on the aluminium surface which blocks its corroding sites. The adsorbed inhibitor film act as a protective layer between the metal and acid medium and prevents the further $\operatorname{corrosion}^{10}$.

Table-1: Inhibition Efficiency on Aluminium in $1 \mathrm{~N} \mathrm{H}_{2} \mathrm{SO}_{4}$ Acid by Mass Loss Measurement at Room Temperature

\begin{tabular}{c|c|c|c|c|c}
\hline $\begin{array}{c}\text { Name of the } \\
\text { inhibitor }\end{array}$ & $\begin{array}{c}\text { Inhibitor } \\
\text { Concentration }(\mathrm{mM})\end{array}$ & $\begin{array}{c}\text { Weight } \\
\text { loss }(\mathrm{g})\end{array}$ & $\begin{array}{c}\text { Corrosion rate } \\
(\mathrm{mmpy})\end{array}$ & $\begin{array}{c}\text { Inhibition } \\
\text { Efficiency }(\%)\end{array}$ & $\begin{array}{c}\text { Surface } \\
\text { coverage }(\theta)\end{array}$ \\
\hline \multirow{3}{*}{\begin{tabular}{c}
3,5 -diethyl 2,6- \\
p-chloro diphenyl \\
piperidin-4-one \\
\cline { 2 - 6 }$(\mathrm{DEPCPN})$
\end{tabular}} & Blank & 0.0030 & 0.0114 & -- & -- \\
\cline { 2 - 6 } & 0.5 & 0.0022 & 0.0083 & 26.67 & 0.2667 \\
\cline { 2 - 6 } & 1.0 & 0.0011 & 0.0417 & 63.33 & 0.6333 \\
\cline { 2 - 6 } & 2.0 & 0.0009 & 0.3413 & 70.00 & 0.7000 \\
\hline
\end{tabular}

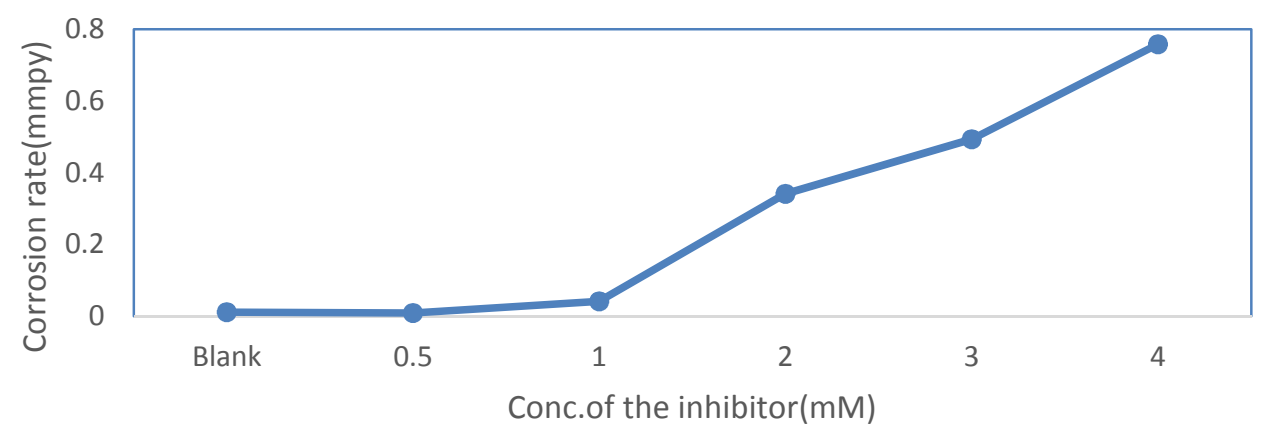

Fig.-3: Effect of Concentration of Inhibitor 3,5-Diethyl 2,6-p-choloro diphenyl piperidin-4-one (DEPCPN) on Corrosion Rate

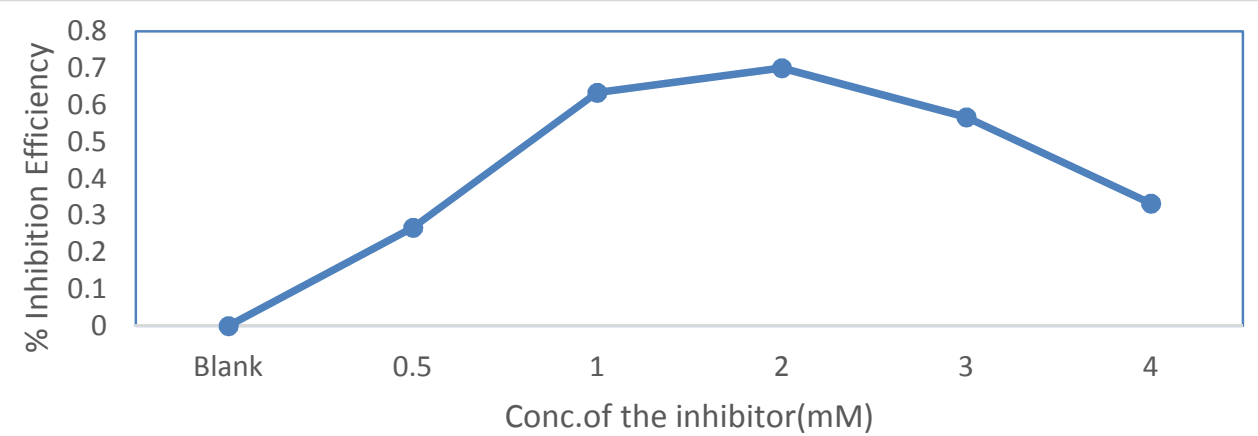

Fig.-4: Effect of Concentration of Inhibitor 3,5-Diethyl 2,6-p-choloro diphenyl piperidin-4-one (DEPCPN) on Inhibition Efficiency 
RASĀYAN J. Chem.

Vol. 12 | No. 2 |565 - 570| April - June | 2019

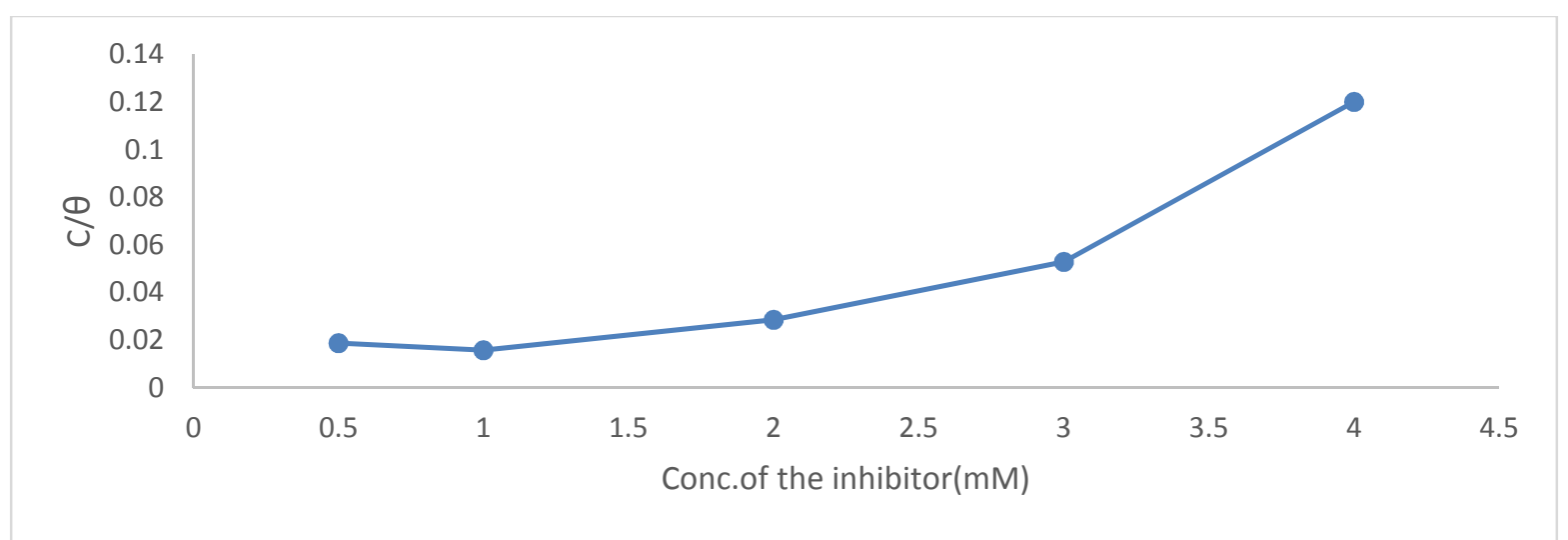

Fig.-5: Adsorption Isotherm

Adsorption isotherm is used to analyze the inhibition mechanism of corrosion inhibitor. It gives the information about the nature of interaction taking place between the adsorbed DEPCPN with the aluminum surface. The obtained data is inferred with different adsorption isotherms to study the inhibition performance of the inhibitor and it is found that the Langmuir adsorption model is well obeyed with the experimental data. The plot of $\mathrm{C} / \theta \mathrm{Vs} \mathrm{C}$ (Fig.-5) is obtained from this study reveals that the inhibition of corrosion of aluminium by the inhibitor DEPCPN.

Table-2: Potentiodynamic Polarization Data of DEPCPN in $1 \mathrm{M} \mathrm{H}_{2} \mathrm{SO}_{4}$ on Aluminium Surface

\begin{tabular}{c|c|c|c|c|c}
\hline $\begin{array}{c}\text { Conc. of } \\
\text { DEPCPN }(\mathrm{mM})\end{array}$ & $-\mathrm{E}_{\text {corr }}(\mathrm{mV})$ & $\begin{array}{c}-\mathrm{I}_{\text {corr }}(\mathrm{mA} \\
\left.\mathrm{cm}^{-2}\right)\end{array}$ & $-\mathrm{b}_{\mathrm{a}}(\mathrm{mV})$ & $-\mathrm{b}_{\mathrm{c}}(\mathrm{mV})$ & $\begin{array}{c}\text { \%Inhibition } \\
\text { Efficiency }\end{array}$ \\
\hline Blank & 0.8309 & 0.0378 & 0.2998 & 0.1188 & --- \\
\hline 0.5 & 0.8302 & 0.0152 & 0.3595 & 0.0967 & 59.70 \\
\hline 1.0 & 0.6119 & 0.0093 & 0.2078 & 0.2158 & 75.39 \\
\hline 2.0 & 0.7428 & 0.0042 & 0.1928 & 0.1307 & 88.89 \\
\hline 3.0 & 0.8061 & 0.0146 & 0,2298 & 0.1158 & 61.30 \\
\hline
\end{tabular}

Figure- 6 shows the potentiodynamic polarization plot of aluminium in $1 \mathrm{~N}_{2} \mathrm{SO}_{4}$ with different concentrations of DEPCPN. The electrochemical quantities are obtained from Tafel extrapolation and linear polarization techniques. The corrosion parameters viz. corrosion potential ( $\left.\mathrm{E}_{\text {corr }}\right)$, corrosion current density $\left(\mathrm{I}_{\text {corr }}\right.$ ), Tafel slopes (ba \& bc) are obtained from the polarization curves. While adding the DEPCPN inhibitor the value of corrosion current density $\left(\mathrm{I}_{\text {corr }}\right)$ decreases.

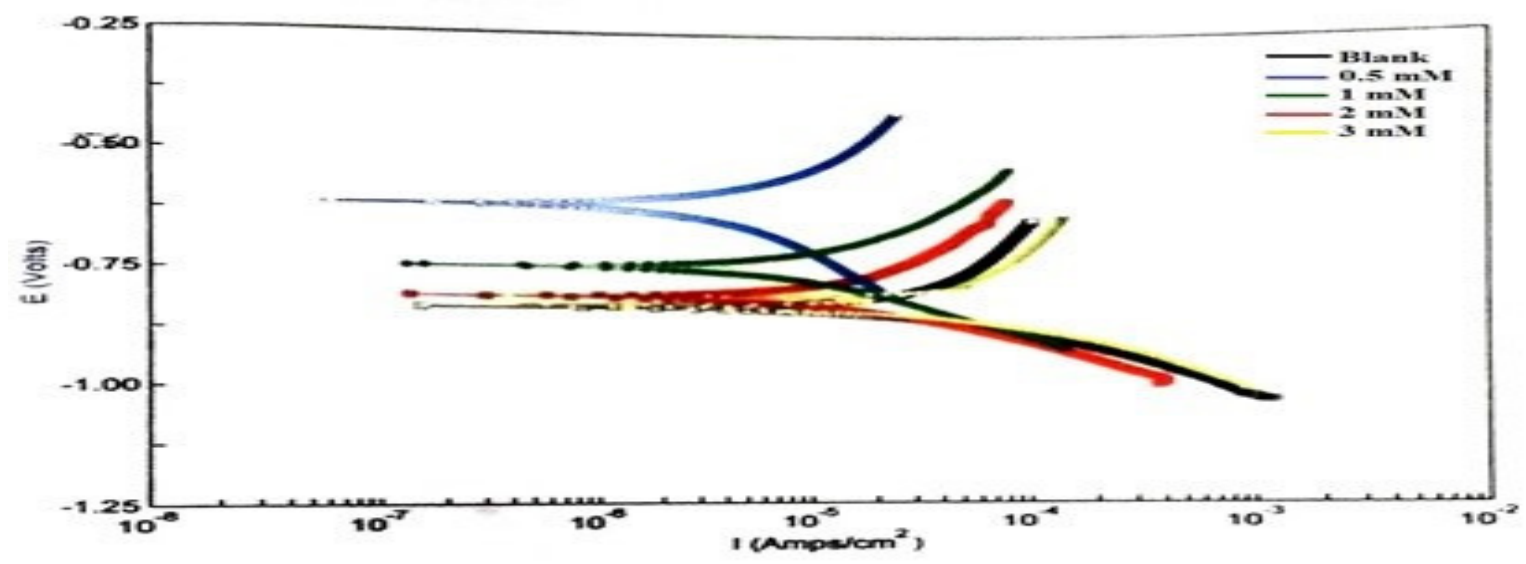

Fig.-6: Potentiodynamic Polarization Curve of DEPCPN on Aluminium Surface

The findings reveal that the inhibitor molecule may get adsorbed on the aluminium surface which hinders the reactive sites of the metal surface without disturbing the reactions taking place at the anodic and cathodic 
sites. The decreasing nature of $I_{\text {corr }}$ value by adding different inhibitor concentration clearly shows the increasing percentage of inhibition efficiency. The chemical adsorption is observed between the reactive sites of aluminum metal and the DEPCPN inhibiting molecule. Blocking of this reactive site always does not shift the cathodic and anodic polarization plots, whereas chemisorption on active sites slightly shifts the slopes. ${ }^{11}$ From the Tafel slopes, the Tafel constants ba and bc are shifted, which discloses that the chemical adsorption may exist between the chlorine substituted organic inhibitor and active sites of the metal surface which may hinder the anodic dissolution which in turn hinders the evolution of hydrogen and makes the organic inhibitor to behave as both anodic and cathodic type inhibitor.

Table-3: Electrochemical Impedance Data for DEPCPN in $1 \mathrm{M} \mathrm{H}_{2} \mathrm{SO}_{4}$ on the aluminium surface

\begin{tabular}{c|c|c|c}
\hline $\begin{array}{c}\text { Concentration of } \\
\text { inhibitor }\end{array}$ & $\mathrm{R}_{\mathrm{ct}}\left(\mathrm{Ohm} . \mathrm{cm}^{2}\right)$ & $\mathrm{C}_{\mathrm{dl}}\left(\mathrm{F}^{* 10^{-5}}\right)$ & $\begin{array}{c}\text { \% Inhibition } \\
\text { Efficiency }\end{array}$ \\
\hline Blank & 94.02 & 8.2933 & -- \\
\hline 0.5 & 612.35 & 1.7610 & 84.65 \\
\hline 1.0 & 1313.21 & 1.3362 & 92.84 \\
\hline 2.0 & 1386.18 & 1.3215 & 93.23 \\
\hline 3.0 & 785.37 & 2.0707 & 88.03 \\
\hline
\end{tabular}

The corrosion tendency of aluminium is examined by AC impedance measurements at room temperature after 10minof immersion. Table-3 shows the result of the Nyquist plot for various concentration of the inhibitor DEPCPN. The impedance parameters like $R_{\mathrm{ct}}, \mathrm{C}_{\mathrm{dl}}$ are noted. Fig.-7 Nyquist impedance spectrum semicircle shape infers by using charge transfer resistance, $R_{c t}$, with the double aye rcapacitor $C_{d l}$ the electrode interface under analysis can conditionally be expressed ${ }^{9}$. The change in double layer capacity $\mathrm{C}_{\mathrm{dl}}$ value infers that the organic inhibitor molecule is adsorbed on the aluminium surface ${ }^{12,13}$. While adding the organic inhibitor molecule the decrease in $\mathrm{C}_{\mathrm{dl}}$ value shows the extent of assimilation of organic inhibiting molecules on the aluminium surface and this is because of the strong chemical bond formation between inhibitor DEPCPN and the aluminium surface that tends to replace the water molecules between the interfaces ${ }^{14}$.

The addition of inhibitor DEPCPN in the uninhibited acid medium for aluminium significantly changes the charge transfer resistance $\left(\mathrm{R}_{\mathrm{ct}}\right)$ values ${ }^{15}$. It is observed that the $\mathrm{R}_{\mathrm{ct}}$ value increases with the increasing concentration of DEPCPN. It reveals that the corroding tendency of aluminium surface in a sulfuric acid medium is influenced by charge transfer process ${ }^{16}$. The findings in the tabulation reveal that the decrease in \%IE when the concentration of DEPCPN reaches optimum level is due to organic inhibitor molecules are desorbed from the aluminium metal surface. The results of the electrochemical method are in good agreement with the mass loss measurement.

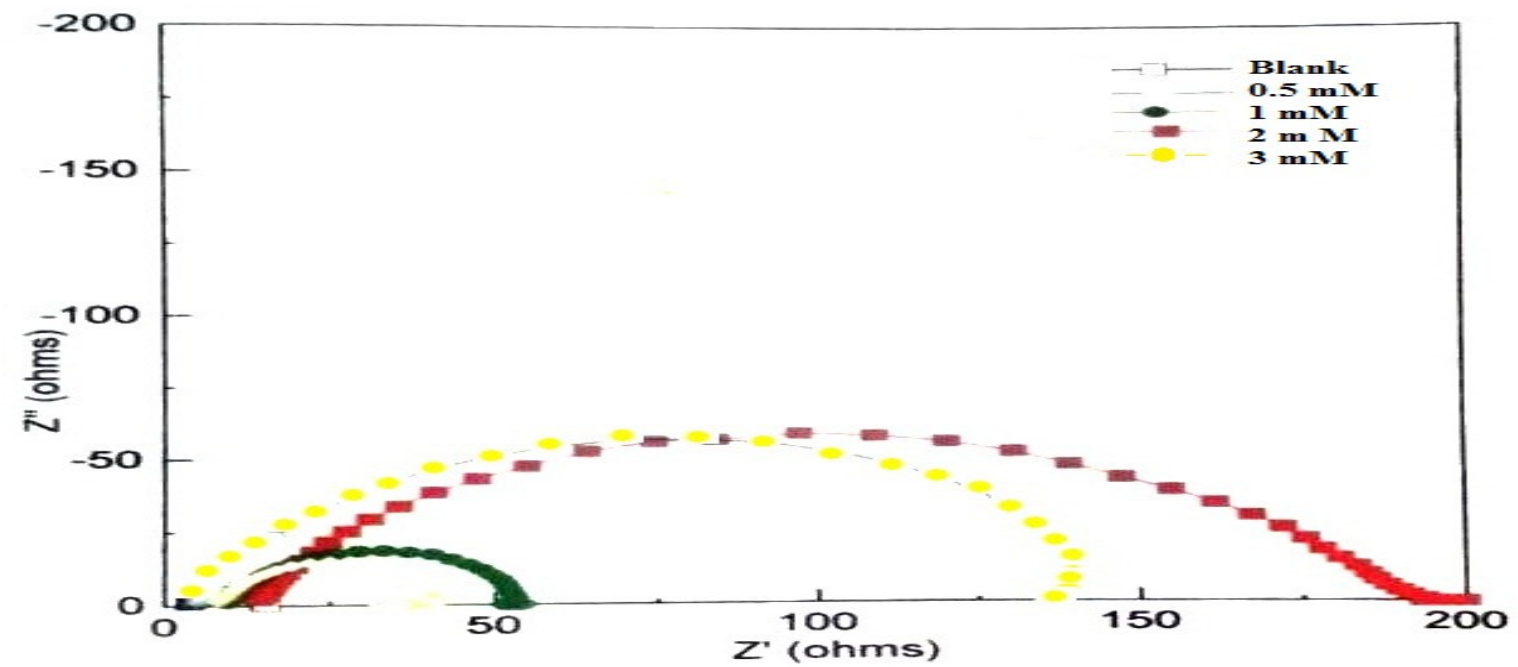

Fig.-7: Nyquist Plot for DEPCPN in $1 \mathrm{M} \mathrm{H}_{2} \mathrm{SO}_{4}$ on Aluminium Surface 
RASĀYAN J. Chem.

Vol. 12 | No. 2 |565 - 570| April - June | 2019

\section{CONCLUSION}

The results from mass loss measurements and potentiodynamic polarization studies and electrochemical impedance reveal that the corrosion inhibition efficiency of the organic inhibitor 3, 5-diethyl 2, 6-diphenyl $p$-chloro Piperidin-4-one (DEPCPN) is observed to increase with increasing inhibitor concentration and maximum efficiency is observed at $2 \mathrm{mM}$ concentration. At higher concentrations, the organic inhibitor molecule may get desorbed from the active site so that the \% IE may decrease. The findings also show that the inhibitor molecule tends to form a protective layer with the metal surface which in turn blocks the active metal sites from corrosion. The adsorption of inhibitor DEPCPN on aluminium surface obeys Langmuir adsorption isotherm. The inhibitor behaves as both anodic and cathodic type inhibitor.

\section{REFERENCES}

1. Guddi Choudhary, Arpita Sharma, Alka Sharma, Int. J. Innov. Res. Sci. Eng. Technol., 2 (2013), DOI:10.15680/IJIRSET.2014.0309048.

2. Christian Vargel, Michel Jacques and Dr. Martin P. Schmidt, Corrosion of Aluminum Elseveir, p.185, (2004).

3. B. Gómez, N. V. Likhanova, M. A. Domínguez Aguilar, O. Olivares, J. M. Hallenand J. M. MartínezMagadán, J. Phys. Chem. A, 109, 8950 (2005), DOI: 10.1021/jp052188k.

4. G. Y. Elewady, Int. J. Electrochem. Sci., 3, 177 (2008).

5. K. F. Khaled, K. Babic-Samardzija, and N. Hackerman. J. Appl. Electrochem. 34,697 (2004).

6. K. Rathidevi and. Jalajaa, International Journal Science and Research, 1852 (2015).

7. H. Zarrok, H. Oudda, A. Zarrouk , R. Salghi , B. Hammouti , M. Bouachrine, Der Pharma Chemica, 3, $576(2011)$.

8. S. Jyothi and K. Rathidevi, Rasayan J. Chem., 10, 1253 (2017), DOI:10.7324/RJC.2017.1041924.

9. R. Venckatesh, P. S. Syed Shabudeen and S. Gopal, E-Journal of Chemistry, 137 (2007), DOI: $10.1155 / 2007 / 789135$.

10. P. Arockiasamy,X. Queen Rosary Sheela,G. Thenmozhi,M. Franco,J. Wilson Sahayaraj,and R. Jaya Santhi,Int. J. Corros., 7 (2014), DOI:10.1155/2014/679192.

11. O. L. Akanji, C.A. Loto, A.P.I. Popoola, M. Abdulwahab, and A.V. Kolesnikov., Asian Journal of Chemistry, 28, 1417 (2016), DOI:10.14233/ajchem.2016.19648.

12. Glory Tharial Xavier, Brindha Thirumalairaj, and Mallika Jaganathan, Int. J. Corros., 15 (2015), DOI: $10.1155 / 2015 / 410120$.

13. D. Jalajaa, J. Mallika and S. Jyothi, Rasayan J.Chem., 10, 1271(2017), DOI: 10.7324/RJC.2017.1041926

14. M. A. Quraishi and D. Jamal, J.Appl. Electrochem., 32, 425 (2002).

15. D. Prabhu and P. Rao, Arab. J. Chem., 10, S2234 (2017), DOI:10.1016/j.arabjc.2013.07.059

16. D. Jalajaa, J. Mallika and S. Jyothi, Rasayan J. Chem.,10, 1271 (2017), DOI:10.7324/RJC.2017.10419

[RJC-4098/2018] 